\title{
Performance Impact Mechanism of Alliance Portfolio Diversity: Mediated by Product Market Power
}

\author{
Xinhua Hu \\ Associate Professor \\ Business School of Southwest \\ University of Political Science and Law \\ Chongqing, 401120 \\ China
}

\begin{abstract}
:
Due to cost and complexity increase brought by diversity, the impact of alliance portfolio diversity on firm performance is uncertain. Extant studies only focus on the direct relationship between the two, which makes the impact mechanism of alliance portfolio diversity unclear, and difficult to enhance value of alliance portfolio diversity. We focus on the performance impact of alliance portfolio functional diversity and investigates whether product market power plays the mediating role between them. Based on the panel data of 278 GEMlisted companies in China, we find that there is the negative relationship between the alliance portfolio resource diversity and firm performance, while product market power plays a mediating role between them. The study complements the exploration of the impact mechanism between alliance portfolio diversity and firm performance, and provides useful thinking for firms to fully explore the potential value of the alliance portfolio resource diversity in the practice.
\end{abstract}

Key words: alliance portfolio function diversity, product market power, performance, impact mechanism

\section{Introduction}

Driven by the motivation of entering new markets and accelerating innovation, strategic alliance has become an important channel for firms to obtain external resources (Rothaermel and Boeker, 2008). Especially for SMEs which lack sufficient resources to develop new products or to meet the challenges of environmental change, strategic alliance provides a potential important mechanism to help them keep up with market demand (Baum, Calabrese and Silverman, 2000). With the accumulation of external network connections, many firms participate in several different alliances at the same time, that is, establishing alliance portfolios, so as to access a wide range of resources and markets (Wassmer, 2010). These strategic alliances not only affect the behavior and performance of enterprises individually, but also influence as a whole (Carpenter, Li and Jiang, 2012).

Diversity is a hot topic in the study of alliance portfolios, it reflects the difference of alliance type and quantity in alliance portfolios, including resource diversity, functional diversity, alliance partner type diversity, alliance governance diversity, etc. (Lee, Kirkpatrick-Husk and Madhavan, 2017). However, extant studies mainly focuses on the direct relationship between alliance portfolio diversity and firm performance, and few literatures have explored the mechanism of alliance portfolio diversity on firm performance, i.e., the channel though which alliance portfolio diversity has a positive or negative impact on performance (Martinez, Zouaghi and Garcia, 2017), which leads to the specific impact of alliance portfolio diversity is not clear, so it is difficult to better tap the potential value of alliance portfolio diversity.

According to the survey of executives, it is found that the acquisition of product market power in practice ranks the third among the main motivations for firms to form strategic alliance (Koza and Lewin, 2000). From the perspective of resource dependence theory, firms can stabilize the flow of resources and enhance product market power by establishing strategic alliances (Davis and Cobb, 2010); in particular, SMEs can enhance their reputation and enhance their negotiation ability in network relations by establishing alliance relations with reputable enterprises (Chen and Chen, 2002). Therefore, the influence of alliance portfolio diversity on firm performance may be mediated by product market power. Although there is a potential mechanism in theory, extant literatures have not explored it from the empirical perspective.

Therefore, the study will focus on the alliance portfolio functional diversity and empirically tests the panel data of 278 GEM listed companies in 
China to explore what characteristics of the alliance portfolio diversity is the root of influencing performance, and then investigate whether the product market power can explain the influence mechanism between alliance portfolio diversity and firm performance. We hope to make up for the research on the influence mechanism between alliance portfolio diversity and firm performance from the theoretical perspective, and better explain the deep-seated logic of the formation of the direct relationship between the two, meanwhile, provide direction to guide and coordinate alliance portfolio diversity more effectively in the practice of strategic alliance, and maximize the effectiveness and value of alliance portfolio diversity.

\section{Theory and hypothesis}

\subsection{Alliance portfolio functional diversity and firm performance}

The Alliance portfolio functional diversity refers to the difference of value chain activities involved in different alliances. The establishment of alliance portfolio to balance different value chain activities is conducive to the synchronous improvement of different operation activities of firms, reducing the ability gap between core businesses and non-core businesses, and has significant advantages for large enterprises (Lavie, Kang and Rosenkopf, 2011).But it has more negative effects on the firms with limited resources and small scale. First, with the increase of alliance portfolio functional diversity, different alliances usually pursue different goals, and the management and coordination requirements tend to be complicated. From the perspective of transaction cost, this includes both internal coordination and coordination with different alliance partners. firms must invest differentiated management resources for different alliances, but they are still troubled by information overload and diseconomies of scale (Ahuja and Lampert, 2001). Secondly, there are potential conflicts between organizational practices among different activities, and participants in different functional alliances have different values, mental models and behavior patterns. With the increase of alliance portfolio functional diversity, information exchange between partners becomes more difficult (Goerzen and Beamish, 2005). Finally, firms should develop different or even conflicting partner selection and performance evaluation criteria for different functional alliances. With the increase of alliance portfolio functional diversity, it is more complex for focus firms to effectively evaluate different alliance partners and alliance performance, and experience is difficult to be transplanted between alliances, which may lead to negative feedback and learning effects among different alliances, and increase the cost of trial and error (Lavie, Kang and Rosenkopf, 2011). SMEs without alliance management experience are more difficult to deal with these potential negative impacts (Dickson, Weaver and Hoy, 2006). Therefore, for SMEs, the higher the alliance portfolio functional diversity, focus firms will face greater coordination difficulty, higher integration cost, and more potential conflicts.

Hypothesis 1: The increase of alliance portfolio functional diversity has a negative impact on firm performance.

\subsection{The mediating effect of product market power}

The value creation of a firm is embedded in the competitive state of its external product market (Makhija, 2003). Therefore, the product market power of a firm is also known as the pricing right within the industry. It comes from the firm's ability to obtain extraordinary rent (higher price) from its customers without significantly reducing the demand, thus giving the firm competitive pricing advantage. To some extent, the product market power of a firm can be used to explain its relative performance. As pointed out in the report of Simon KucherandPartners (2017), the average profit marginof companies with high market power (pricing power) is $25 \%-33 \%$ higher than that of firms without pricing power. Makhija (2003) pointed out that, even in a relatively changing environment, the product market power pattern and performance reflection between existing enterprises are unlikely to change rapidly. Therefore, firms with higher product market power can generally maintain higher performance for a long time.

Shaping differentiated products / services is an important driving factor for firms to form product market power. The unique and high-value product line, strong brand and other differentiation elements of an enterprise are the signs of strong pricing ability and great competitive advantage (Datta et al., 2011). For firms in competitive rather than monopoly industries, especially SMEs with small market share, the acquisition of product market power mainly depends on their specific skills to meet the market needs, form differentiated product advantages, and enable customers to deeply understand their products and even their specialties. For example, the differentiation advantage of a product manufacturer will make it have a greater market power than the middlemen, because the middlemen can obtain greater profits from the sale of its goods and expect to establish a close trading relationship with it (Shervani et al., 2007). 
Therefore, by shaping product differentiation, firms can create more significant competitive advantages, have stronger pricing ability or cost transfer ability, that is, greater product market power, so as to have greater profit space, or more transfer costs to customers when external costs increase. On the contrary, it is difficult for firms with insufficient product market power to transfer the external impact to the downstream.

However, the improvement of the alliance portfolio functional diversity has a negative impact on focus firms' product market power. The increase of alliance portfolio functional diversity aggravates the complexity of management, increases the cost of internal and external coordination, and is not conducive to firms to allocate more resources to specific key activities or specific assets, which are necessary support for firms to achieve key competitive positioning, 1985, which is disadvantageous to meet the needs of customers in specific markets and surpass competitors. Therefore, it is more likely to reduce the focus' firms' product market power, and then decrease performance. Especially for SMEs, when they compete for limited resources, they will gradually concentrate their limited resources on the most critical activities or areas (Davcik et al., 2015). When participating in too diversified external cooperation activities, it will disturb the distribution of their key resources, and restrict the access to resources of key activities. Compared with the firms that build alliance portfolio closely around the core business activities and focus on strengthening the core competitive advantage, the firms that have constructed diversified alliance portfolio function will lose its focus on external resource acquisition and internal resource allocation, and the growth of core competitiveness will be limited, which will affect their value provision and their product market power will also face negative effect. Therefore, the more types of external alliance activities a firm enters, the more likely it will weaken the ability of its key activity areas, reduce its product market power, and have a negative impact on its performance. Hence, we get hypothesis 2 .

Hypothesis 2: Product market power plays a mediating role in the negative relationship between alliance portfolio functional diversity and firm performance.

\section{Methodology}

\subsection{Sample and data}

The data of this study mainly come from the "Annual Report and Strategic Alliance Database of GEM Listed Companies of China", which is independently established by the author's team, funded by the National Natural Science Foundation of China. The database benefits from the experiences ofMerger and Alliance Database of Securities Data Corporation (SDC), tracks the information of alliance announcement of listed companies, extracts and codes them, and forms a matrix structured quantitative database. A total of 3354 annual reports and 5389 alliance announcements published by 448 GEM listed companies in China have been coded. The sample time range covers October 30, 2009 to June 20, 2017, which constitutes the panel data.

The independent variables alliance portfolio functional diversity and control variable alliance portfolio size, are both from the above coded database. The mediation variables, product market power and other control variables are calculated based on the relevant data of CSMAR Economic and Financial Database. Because the GEM listed companies have the behavior of establishing strategic alliance every year, we take the alliance portfolio constructed by the firms at the end of each year as the sample point to accumulate the alliances. Financial and insurance firms are excluded from the sample, because they are significant different in debt and capital structure; firms without alliance announcement in the sample period are excluded; in order to ensure the size of the industry and reduce the impact of single company on the estimation of industry level variables, we follow the common practice (Chen and Miller, 2007), eliminated small industries with less than five firms; excluding firms that had shell buying and selling transactions or delisted during this period, so as to ensure the continuity of firm information; as there were lag variables in the model, firms with only one year's data were excluded to ensure each sample firm has at least two years of data. Finally, we selected 278 sample enterprises which built alliance portfolio from 2010 to 2016 , and nearly $90 \%$ of them have a time span of more than 3 years. After calculating the diversity of alliance portfolio, the 278 firms have 1580 observations, which constitute the unbalanced panel data.

\subsection{Dependent variable}

Performance. Return on investment capital (ROIC) is widely used to measure firm performance, which is an important indicator of long-term financial performance and reflects firms' value creation ability. The specific calculation method is to divide the operating profit before interest and after tax by the invested capital. The advantage of this index relative to the rate of return on net assets (ROE) is that the influence of capital structure is eliminated. 


\subsection{Independent variable}

Alliance portfolio functional diversity. Based on the classification of Lavie et al. (2011) and Jiang et al. (2010), we classify the alliance portfolio functional categories into five categories: supply, production, $\mathrm{R} \& \mathrm{D}$, marketing and sales, and others. Based on this classification, we carried out the text coding of the alliance announcement of GEM listed companies, and identified the value activity function of the alliance according to the alliance content described by the focus firms.

Based on the above-mentioned data collection, we use the Blau Index to calculate degree of alliance portfolio functional diversity, which is

$$
\mathrm{D}=1-\sum \mathrm{p}_{\mathrm{i}}^{2}(1)
$$

Where $\mathrm{D}$ is the degree of diversity, $\mathrm{P}$ is the proportion of a given category, and $\mathrm{I}$ is the total number of different functional categories in an alliance portfolio. This variable ranges from 0 (completely homogeneous) to 1 (completely heterogeneous, evenly distributed across all categories). According to the extant literatures (Sampson, 2007), the impact of strategic alliance on firm performance has a lag effect, therefore, we use the data of alliance portfolio functional diversity one year ahead of performance.

\subsection{Mediation variable}

The widely accepted index, i.e. Lerner Index adjusted by industry, is used to measure product market power (Datta et al., 2011; Pan et al., 2019), and the formula is as follows:

$$
L I=\frac{\mathrm{P}-\mathrm{MC}}{\mathrm{P}}(2)
$$

Where LI is Lerner Index, P is the price of products / services provided by the focus firm, and MC is the marginal cost of products / services provided by the focus firm. The range of Lerner Index is from 0 to 1, and shows a single corresponding relationship with product market power. In a fully competitive market, Lerner Index is 0.

Since the marginal cost data of firms are difficult to obtain, we assume that the average variable cost is equal to the marginal cost (Carlton and Perloff, 2005), and use operating profit margin as an alternative indicator to express Lerner Index, which is widely used in financial study as a measurement index of product market power (Pan et al., 2019). If the annual sales volume of a firm is expressed by annual operating revenue, the calculation of Lerner Index is published as follows:

$$
L I=\frac{\text { sales income }- \text { sales cost }}{\text { sales income }}(3)
$$

Due to the influence of factors other than market forces, the profit margins of different industries may be different in structure (Gaspar and Massa, 2006), following the common practice in recent years (Datta et al, 2011), the Lerner Index of the focusfirm is adjusted by subtracting the average Lena Index weighted by sales of all listed companies in the same industry, so as to better capture the difference of product market power in the industry.

$$
M P_{i, j, t}=L I_{i, j, t}-\sum_{i=1}^{n} \omega_{i, j, t} L I_{i, j, t}(4)
$$

Where $M P_{i, j, t}$ represents the product market power of firm $i$ in the industry $j$ in the year $t$, and $L I_{i, j, t}$ represents the Lerner Index of firm $i$ calculated in the formula (3), , $\omega_{i, j, t}$ represents the percentage of sales of firm $i$ to all listed companies in its industry in year $t$, and $n$ is the total number of firms in firm $i$ 's industry.

According to the Guidelines for Industry Classification of Listed Companies (2012 Edition) issued by China Securities Regulatory Commission (CSRC), since the number of sample firms in the manufacturing industry is far more than that of other industries, in order to distribute evenly, the manufacturing industry is reserved to level 2 code by referring to Zhu et al. (2018), and the manufacturing industry is kept at level 1 code. Finally, all sample firms are divided into 29 industries (including 18 manufacturing industries subdivided into secondary code and 11 primary code industries).

\subsection{Control variables}

We control alliance portfolio size, R\&D investment, firm size, firm age, last year performance (ROE), market share, sales growth rate, and year and industry effects. The alliance portfolio size is measured by the number of alliance partners in alliance portfolio referring to Jiang et al. (2010), and consistent with the alliance portfolio diversity, the data of one year in advance (t-1) is used. $R \& D$ investment is measured by the proportion of $R \& D$ expenditure in operating revenue, and considering the lag of $R \& D$ investment, the data of one period ( $t-1$ year) in advance is used. 
Firm age is measured by the natural logarithm of the number of years from the establishment year to the data year, and firm size is measured by the natural logarithm of the total assets of the enterprise (unit: RMB million). The sales growth rate is measured by the ratio of the difference between the sales of the firm in the current year minus that of the previous year and the sales of the previous year. the last year ROE (return on net assets) of the firm is calculated by the ratio of the firm's net profit to the owner's equity. To measure the market share, the annual operating income of the focus firm is divided by the sum of the operating income of all listed firms in the industry.

\section{Results}

\subsection{Descriptive statistics and correlation analysis}

Table 1 presents the descriptive statistics and correlation matrix for all variables.All variables were significantly correlated with firm performance (ROIC) $(\mathrm{p}<0.01)$. There is a negative correlation between the alliance portfolio functional diversity and the performance, which indicates that hypothesis 1 is possible. The alliance portfolio functional diversity is negatively correlated with product market power, while product market power is positively correlated with performance, indicating that hypothesis 2 is possible. Among the control variables, the last year performance, sales growth rate and market share are positively correlated with firm performance, but alliance portfolio size, firm age, firm size, R\&D investment are negatively correlated with enterprise performance. In order to avoid multicollinearity among variables, the highest value of variance expansion factor (VIF) of all variables is 2.11 and the average is 1.61. Therefore, there is no serious multicollinearity, which meets the requirements of the model.

Table1Descriptive statistics and correlation analysis

\begin{tabular}{|c|c|c|c|c|c|c|c|c|c|c|c|c|}
\hline & Mean & SD & $\mathrm{y}$ & $\mathrm{x}$ & me & $\mathrm{c} 1$ & $\mathrm{c} 2$ & $\mathrm{c} 3$ & $\mathrm{c} 4$ & $\mathrm{c5}$ & c6 & $\mathrm{c} 7$ \\
\hline $\mathrm{ROA}(\mathrm{y})$ & 0.064 & 0.050 & 1 & & & & & & & & & \\
\hline $\begin{array}{ll}\text { Alliance } & \text { portfolio } \\
\text { functional } & \\
\text { diversity }(\mathrm{x}) & \end{array}$ & 0.320 & 0.316 & $-\overline{0.130 * * *}$ & 1 & & & & & & & & \\
\hline $\begin{array}{l}\text { Product market power } \\
\text { (me) }\end{array}$ & 0.137 & 0.152 & $0.552 * * *$ & - & 1 & & & & & & & \\
\hline $\begin{array}{l}\text { Alliance } \\
\text { size }(\mathrm{c} 1)\end{array}$ & 2.781 & 4.279 & $-0.055^{* *}$ & $0.470 * * *$ & $-\overline{0.077 * * *}$ & 1 & & & & & & \\
\hline $\mathrm{R} \& \mathrm{D}$ investment(c2) & 0.069 & 0.063 & $-\overline{0.158 * * *}$ & -0.008 & $-\overline{0.189 * * *}$ & $-0.067 * *$ & 1 & & & & & \\
\hline Firm size (c3) & 7.308 & 0.732 & $-0.057 * *$ & $0.388 * * *$ & $0.071 * * *$ & $0.441 * * *$ & $\overline{0} .111 * * *$ & 1 & & & & \\
\hline Firm age (c4) & 2.525 & 0.322 & $\overline{0.117 * * *}$ & $0.171 * * *$ & $\overline{0} .128 * * *$ & $0.141 * * *$ & $0.060 * *$ & $0.235 * * *$ & 1 & & & \\
\hline Sales growth rate (c5) & 0.253 & 0.378 & $0.147 * * *$ & 0.039 & $0.055^{* *}$ & $0.057 * *$ & 0.016 & $0.272 * * *$ & $0.060 * *$ & 1 & & \\
\hline ROE(c6) & 0.090 & 0.073 & $0.573 * * *$ & $-\overline{0.188 * * *}$ & $0.337 * * *$ & $-\overline{0} 082 * * *$ & $-\overline{0.131 * * *}$ & 0.028 & $-\overline{0.155 * * *}$ & -0.004 & 1 & \\
\hline Market share (c7) & 0.004 & 0.008 & $0.119 * * *$ & $0.083 * * *$ & 0.011 & $0.231 * * *$ & $0.173 * * *$ & $0.243 * * *$ & -0.041 & $0.114 * * *$ & $0.087 * * *$ & 1 \\
\hline
\end{tabular}

*** $\mathrm{p}<0.01, * * \mathrm{p}<0.05, * \mathrm{p}<0.1$ 。

\subsection{Regression analysis}

The panel data test needs to consider the problem of model selection. Through the Hausman test on the model, the result is significant at the level of $1 \%$, which indicates that the fixed effect model is better than the random effect model. Therefore, we chose the fixed effect model to verify the hypothesis proposed above. In order to test the mediating effect, we use the method of causality stepwise regression (Barron and Kenny, 1986) to test whether product market power plays an mediating role between the alliance portfolio functional diversity and firm performance. The results are shown in Table 2.

The results of model 2 show that the coefficient of alliance portfolio functional diversity is negative and significant $(\mathrm{p}<0.01)$, which indicates that the alliance portfolio functional diversity has a negative impact on firm performance, and hypothesis 1 is verified.

Model 2, model 3 and model 4 are three-stage stepwise regression results to test the mediating effect. Based onsignificance of model 2, model 3 takes product market power as the explanation mediator, and the coefficient of alliance portfolio functional diversity is significantly negative $(\mathrm{P}<0.05)$, which is consistent with the direction of model 2. 
In model 4, the alliance portfolio functional diversity and product market power are regressed to firm performance at the same time, and the interaction term between product market power and alliance portfolio functional diversity is added to the model. The results show that there is a significant positive relationship between product market power and performance $(\mathrm{P}<0.01)$, while The relationship between alliance portfolio function diversity and firm performance is still negative, but the influence is weakened (coefficient changes from - 0.015 to - 0.009), and the significance decreases $(\mathrm{P}<0.05)$ The interaction of product market power and alliance portfolio functional diversity has no significant impact on performance, which indicates that the relationship between product market power and performance is not affected by the contingency of alliance portfolio functional diversity. It can be concluded that the product market power plays a partial mediating role in the negative impact of alliance portfolio functional diversity on firm performance. In addition, after adding product market power, the fitting degree of model 4 is significantly better than that of model 2 , so hypothesis 2 is supported.

\subsection{Robustness}

We carried out the robustness test by replacing the dependent variables. We use return on total assets (ROA) to replace ROIC, which is considered as a key indicator to measure whether a firm manages resources effectively (Combs et al., 2005). The regression results are shown in Table 3.Model (1), (2) and (3) in Table 3 are the three steps to test the mediating effect by stepwise regression method. Model (1) and (2) show that the alliance portfolio functional diversity has a negative relationship with ROA and product market power. When the alliance portfolio functional diversity and product market power return to ROIC at the same time, there is a significant positive relationship between product market power and ROA, the relationship between alliance portfolio functional diversity and ROA remains negative, but the influence is weakened (coefficient changes from - 0.014 to - 0.008), and the interaction ofalliance portfolio functional diversity and product market power is not significant.Therefore, it shows once again that the negative influence of product market power of alliance portfolio functional diversity affects firm performance through the mediating role of product market power, that is, the results of this study have good robustness.

Table 2 Results of regression

\begin{tabular}{|c|c|c|c|c|}
\hline & ROIC & & $\begin{array}{l}\text { Product market } \\
\text { power }\end{array}$ & ROIC \\
\hline & Model 1 & Model 2 & Model 3 & Model 4 \\
\hline Alliance portfolio size & $-\overline{0} 001 * * *$ & $-0.001 * * *$ & -0.002 & $-0.001 * *$ \\
\hline R\&D investment & $-\overline{0.136 * * *}$ & $-0.128 * * *$ & $-0.593 * * *$ & -0.006 \\
\hline Firm size & $-0.007 * *$ & $-0.006^{*}$ & $0.040 * * *$ & $-0.014 * * *$ \\
\hline Firm age & $0.014 * * *$ & $0.018 * * *$ & $-0.035 * *$ & $0.026 * * *$ \\
\hline Sales growth rate & $0.030 * * *$ & $0.030 * * *$ & $-0.034 * * *$ & $0.023 * * *$ \\
\hline ROE & $0.170 * * *$ & $0.167 * * *$ & $0.175^{*}$ & $0.131 * * *$ \\
\hline Market share & 0.136 & 0.107 & $-3.386 *$ & $0.814^{*}$ \\
\hline Alliance portfolio functional diversity & & $-0.015 * * *$ & $-0.035 * *$ & $-0.009 * *$ \\
\hline Product market power & & & & $0.207 * * *$ \\
\hline $\begin{array}{l}\text { Alliance portfolio functional diversity* Product } \\
\text { market power }\end{array}$ & & & & 0.001 \\
\hline $\mathrm{R}^{2}$ & & 0.194 & 0.135 & 0.525 \\
\hline $\mathrm{F}(\mathrm{P})$ & & $\begin{array}{l}13.816 \\
(0.000)\end{array}$ & $9.446(0.000)$ & $46.644(0.000)$ \\
\hline Samples & & 278 & 278 & 278 \\
\hline
\end{tabular}

$* * * \mathrm{p}<0.01, * * \mathrm{p}<0.05, * \mathrm{p}<0.1$ 。 
Table 3 Results of robustness test

\begin{tabular}{llll}
\hline & ROA & Product market power & ROA \\
\hline & Model $(1)$ & Model $(2)$ & Model $(3)$ \\
\hline Alliance portfolio size & $-0.001^{* *}$ & -0.002 & $-0.001^{* *}$ \\
R\&D investment & $-0.112^{* * *}$ & $-0.593^{* * *}$ & 0.002 \\
Firm size & $-0.005^{*}$ & $0.040^{* * *}$ & $-0.013^{* * *}$ \\
Firm age & 0.007 & $-0.035^{* *}$ & $0.014^{* * *}$ \\
Sales growth rate & $0.029^{* * *}$ & $-0.034^{* * *}$ & $0.023^{* * *}$ \\
ROE & $0.209^{* * *}$ & $0.175^{*}$ & $0.176^{* * *}$ \\
Market share & 0.019 & $-3.386^{*}$ & $0.660^{*}$ \\
Alliance portfolio functional diversity & $-0.014^{* *}$ & $-0.035^{* *}$ & $-0.008^{* *}$ \\
Product market power & & & $0.191^{* * *}$ \\
Alliance portfolio functional diversity * Product market power & & & 0.000 \\
$\mathrm{R}^{2}$ & 0.283 & 0.135 & $0.593^{* *}$ \\
$\mathrm{~F}(\mathrm{P})$ & $30.821(0.000)$ & $9.446(0.000)$ & $63.719(0.000)$ \\
Samples & 278 & 278 & 278 \\
\hline
\end{tabular}

\subsection{Discussion}

The results show that the increase of alliance portfolio functional diversity will bring negative impact on performance. Although the alliance portfolio functional diversity can take into account different value chain activities, such as Xia and Dimov (2019) found that it can help enterprises survive better during the economic crisis, Jiang et al. (2010) believed that it can promote the growth of enterprise profits, but the findings of this study are opposite. This may be because, on the one hand, the samples of this study are mainly SMEs, which lack advantages in size and duration, lack of alliance management experience and ability, and are difficult to effectively integrate different types of alliance activities; on the other hand, it may be that these enterprises have no obvious competitive advantage in the market, which can be seen from their market share that is just $0.4 \%$ on average. However, the establishment of alliances on too many different activities disperses their resources, which makes it more difficult for them to form core competitiveness in specific fields. Therefore, although the growth of balancing different value chain functions has potential benefits, it is beyond their ability, which leads to the damage of firm performance.

The mediating effect test shows that product market power plays a mediating role between alliance portfolio functional diversity and firm performance. Due to the balance between exploration activities and exploitationactivities sought by the alliance portfolio functional diversity, the former helps to enhance the value of products / services, while the latter focuses on improving operational efficiency and reducing the cost of products / services. However, this balance has not achieved its purpose overall. On the one hand, it may be that exploration activities have failed to achieve the expected level of product / service differentiation, On the other hand, it may be that the focus firm has paid too much cost to enter different types of alliance activities, which also makes the price difficult to maintain above the marginal cost. From the perspective of strategy and alliance matching, Yamakawa et al. (2011) pointed out that, the different competitive strategies adopted by firms and the different competitive environments faced by firms should be effectively matched with exploration alliances and exploitation alliances in order to obtain greater profits. It is possible to break the match by balancing different types of alliance activities, which will damage the product market power and firm performance.

\section{Conclusion and future research}

We take 278 GEM listed firms of China as samples, tests the relationship between the alliance portfolio functional diversity and firm performance, finds that there is a negative relationship between alliance portfolio functional diversity and firm performance, further investigation shows that product market power plays a partial mediating rolein their relationship.

\subsection{Theoretical contribution}

Firstly, we measure the alliance portfolio functional diversity with more detailed dimensions, takes MEs as the main samples, enriches the relevant study on balanced exploration alliances and exploitation alliances, as well as balancing core value chain activities and non-core value chain activities.

Secondly, we supplement the existing literatures with exploring the impact mechanism of alliance portfolio diversity. 
Existing literatures mainly discusses the direct impact of alliance portfolio diversity on firm performance, and has not deeply analyzed the influence mechanism, that is, it only answers the question of "what" but not "how". Although some studies have proposed that enhancing product market power is one of the key motivations for firms to build alliances (Hillman et al., 2009), it has not been empirically explored whether product market power plays a mediating role between alliance portfolio diversity and performance, that is, it is not clear whether alliance portfolio diversity can ultimately affect performance through influencing product market power. We find that the alliance portfolio functional diversity influences firm's product market power and then the performance, thus complement existing literatures with the exploration of the mechanism.

\subsection{Managerial implications}

We also give useful implications to firms' practice. On the one hand, enterprises should build alliance portfolio around a few functional areas, strengthen and highlight the advantages of a few areas. On the other hand, managers should focus on enhancing the differentiated value of products / services through alliance portfolio. Because the product market power plays the mediation role between alliance portfolio diversity and firm performance, for the firms in competitive industries, its product market power mainly comes from differentiated products or services, providing customers with higher value than competitors, thus enhancing customer dependence and increasing switching cost. Therefore, managers should focus on improving the differentiated value of products or services to customers by building alliance portfolio to obtain diversified resources. For example, through the construction of alliance portfolio, firms should strengthen innovation and improve customers' brand awareness (legitimacy), to enhance the bargaining power relative to customers and obtain more market premium.

\subsection{Limitations and future directions}

Several limitations of this study and suggestions for future research should be acknowledged. The first is the limitation of the data. Owing to the alliance data used are from firms'announcement, it may not reflect the whole picture of theiralliance portfolio, that is, some alliances have not been announced or the announced alliance has not been implemented. In the future, the database will be dynamically updated every year to obtain alliance information from a wider range of channels to provide more abundant data for further in-depth research.

Secondly, the influence of external environmental factors is not considered. We didn't consider the influence of competitive environment and industry life cycle, which may promote or restrict firm's alliance activities. In the future, we will try to bring the external environmental factors into the research, to explore the differences of alliance portfolio construction behavior under different institutional context, competition environment and industrial stages, and then explore the impact on enterprise performance.

\section{References}

Ahuja, G., Lampert, M. C. Entrepreneurship in the large corporation: A longitudinal study of how established firms create breakthrough inventions[J]. Strategic Management Journal, 2001, 22(6- 7):521-543.

Baron, R. M., Kenny, D. A. The moderator-mediator variable distinction in social psychological research: conceptual, strategic, and statistical considerations[J]. Journal of personality and social psychology, 1986, 51(6):1173-1182.

Baum J. A., Calabrese T., Silverman B. S. Don't go it alone: Alliance network composition and startups' performance in Canadian biotechnology[J]. Strategic Management Journal, 2000, 21(3):267-294.

Carlton, D., Perloff, J. Modern Industrial Organization (4th ed.) [M]. Boston: Pearson/Addison-Wesley, 2005.

Carpenter, M. A., Li, M., Jiang, H. Social network research in organizational contexts: A systematic review of methodological issues and choices[J]. Journal of Management, 2012, 38(4): 1328-1361.

Chen, H., Chen, T. J. Asymmetric strategic alliances: A network view[J]. Journal of Business Research, 2002, 55(12):1007-1013.

Chen, W. R., Miller, K. D. Situational and institutional determinants of firms' R\&D search intensity[J]. Strategic Management Journal, 2007, 28(4): 369-381.

Combs, J. G., Russell, C. T., Shook, C. L. The dimensionality of organizational performance and its implications for strategic management research[A]. In: Research methodology in strategy and management[C]. Emerald Group Publishing Limited, 2005, 259-286. 
Datta, S., Iskandar-Datta, M., Sharma, V. Product market pricing power, industry concentration and analysts' earnings forecasts[J]. Journal of Banking Finance, 2011, 35(6): 1352-1366.

Davcik, N. S., Vinhas, da Silva. R, Hair, J. F. Towards a unified theory of brand equity: conceptualizations, taxonomy and avenues for future research[J]. Journal of Product Brand Management, 2015, 24(1): 3-17.

Davis, G. F., Cobb, J. A. Corporations and Economic Inequality Around the World: The Paradox of Hierarchy[J]. Research in Organizational Behavior, 2010, 30:35-53.

Dickson P. H., Weaver K. M., Hoy F. Opportunism in the R\&D alliances of SMEs: The roles of the institutional environment and sme size[J]. Journal of Business Venturing, 2006, 21(4):487-513.

Gaspar, J. M., Massa, M. Idiosyncratic volatility and product market competition[J]. The Journal of Business, 2006, 79(6):3125-3152.

Goerzen, A., Beamish, P. W. The effect of alliance network diversity on multinational enterprise performance[J]. Strategic Management Journal, 2005, 26(4):333-354.

Hillman, A. J., Withers, M. C., Collins, B. J. Resource dependence theory: A review[J]. Journal of Management, 2009, 35(6):1404-1427.

Jiang, R. J., Tao, Q. T., Santoro, M. D. Alliance portfolio diversity and firm performance[J]. Strategic Management Journal, 2010, 31(10):1136-1144.

Koza, M., Lewin, A. Managing partnerships and strategic alliances: raising the odds of success[J]. European Management Journal, 2000, 18(2):146-151.

Lavie, D., Kang, J., Rosenkopf, L. Balance within and across domains: The performance implications of exploration and exploitation in alliances[J]. Organization Science, 2011, 22(6): 1517-1538.

Lee, D., Kirkpatrick-Husk, K., Madhavan, R. Diversity in alliance portfolios and performance outcomes: a metaanalysis[J]. Journal of Management, 2017, 43(5):1472-1497.

Makhija, M. Comparing the resource- based and market- based views of the firm: empirical evidence from Czech privatization[J]. Strategic Management Journal, 2003, 24(5):433-451.

Martinez, M. G., Zouaghi, F., Garcia, M. S. Casting a wide net for innovation: mediating effect of R\&D human and social capital to unlock the value from alliance portfolio diversity[J]. British Journal of Management, 2019, 30(4):769-790.

Pan, Y., Gruca, T. S., Rego, L. Pricing Power: Measures, Trends and Influences on Firm Value[M]. Cambridge, MA: Marketing Science Institute. 2019.

Rothaermel, F. T., Boeker, W. Old technology meets new technology: Complementarities, similarities, and alliance formation[J]. Strategic Management Journal, 2008, 29(1): 47-77.

Sampson, R. C. R\&D alliances and firm performance: The impact of technological diversity and alliance organization on innovation[J]. Academy of Management Journal, 2007, 50(2):364-386.

Shervani, T. A., Frazier, G., Challagalla, G. The moderating influence of firm market power on the transaction cost economics model: an empirical test in a forward channel integration context[J]. Strategic Management Journal, 2007, 28(6): 635-652.

Wassmer U. Alliance portfolios:A review and research agenda[J]. Journal of Management, 2010, 36(1):141-171.

Xia, T., Dimov, D. Alliances and survival of new biopharmaceutical ventures in the wake of the global financial crisis[J]. Journal of Small Business Management, 2019, 57(2):362-385.

Yamakawa, Y., Yang, H., Lin, Z. J. Exploration versus exploitation in alliance portfolio: Performance implications of organizational, strategic and environmental fit[J]. Research Policy, 2011, 40(2):287-296.

Zhu Z., Li X., Ye W. "Support the horse, send a journey": Strategic change and paternalism in the intergenerational inheritance of family enterprises [J]. Management World, 2018, 11:65-79 